\title{
Goserelin promotes the apoptosis of epithelial ovarian cancer cells by upregulating forkhead box 01 through the PI3K/AKT signaling pathway
}

\author{
NING ZHANG ${ }^{1,2}$, JUNJUN QIU ${ }^{1,2}$, TINGTING ZHENG ${ }^{1,2}$, XIAODAN ZHANG $^{1,2}$, \\ $\mathrm{KEQIN} \mathrm{HUA}^{1,2^{*}}$ and YING ZHANG ${ }^{1,2^{*}}$ \\ ${ }^{1}$ Obstetrics and Gynecology Hospital, Fudan University, Shanghai 200011; \\ ${ }^{2}$ Shanghai Key Laboratory of Female Reproductive Endocrine Related Disease, Shanghai 200011, P.R. China
}

Received June 10, 2017; Accepted December 4, 2017

DOI: $10.3892 /$ or.2017.6159

\begin{abstract}
Gonadotropins, including luteinizing hormone (LH) and follicle stimulating hormone (FSH), are conducive to the growth of ovarian cancer based on the 'gonadotropin theory' and are regulated by gonadotropin-releasing hormone $(\mathrm{GnRH})$. The present study was carried out to investigate the effect of goserelin, a GnRH agonist, on the apoptosis of epithelial ovarian cancer (EOC) cells and the underlying in vitro and in vivo mechanisms. Through flow cytometry, Hoechst staining and TUNEL staining, we demonstrated that goserelin promoted the apoptosis of EOC cells both in vitro and in vivo. Through human apoptosis gene PCR array, we verified that the promotion of EOC cell apoptosis by goserelin was linked to the upregulation of members of the tumor necrosis factor (TNF) and TNF receptor superfamilies, which have been identified as downstream targets of forkhead box O1 (FOXO1). Goserelin enhanced FOXO1 expression, and siRNA-mediated knockdown of FOXO1 abrogated the induction of apoptosis by goserelin. Moreover, goserelin decreased AKT activity, and FOXO1 upregulation by goserelin was dependent on the phosphatidylinositol 3-kinase (PI3K)/AKT pathway. In vivo, the expression of key factors in the PI3K/AKT/FOXO1 pathway was consistent with that observed in vitro. In conclusion, our data suggested that goserelin may promote EOC cell apoptosis by upregulating FOXO1 through the PI3K/AKT signaling pathway. We believe that GnRH agonists may be potential
\end{abstract}

Correspondence to: Dr Keqin Hua or Dr Ying Zhang, Department of Gynecology, Obstetrics and Gynecology Hospital, Fudan University, 419 Fangxie Road, Shanghai 200011, P.R. China

E-mail: huakeqinjiaoshou@163.com

E-mail: 13818218839@163.com

*Contributed equally

Key words: gonadotropin-releasing hormone agonist, goserelin, epithelial ovarian cancer, apoptosis, forkhead box O1, PI3K/AKT signaling pathway antitumor agents, and key factors in the PI3K/AKT-FOXO1 pathway may also be novel therapeutic targets for the treatment of EOC.

\section{Introduction}

Epithelial ovarian cancer (EOC) accounts for $90 \%$ of all ovarian cancer cases, and is one of the three most common gynecological malignancies (1). EOC has a poor prognosis and is the leading cause of death from gynecologic cancers. Although advanced surgical techniques and newly emerging targeted therapies have improved patient outcomes, the 5-year survival rate for EOC patients is still low, at approximately $30-40 \%(2,3)$. In addition, the precise molecular mechanisms underlying the biological behavior of EOC remain unclear. Several hypotheses have been proposed to explain the etiology of EOC, such as the incessant ovulation hypothesis (4), the gonadotropin theory (5) and the sex-steroid hormone hypothesis (6). Increasing basic and epidemiological evidence has shown that the enriched hormonal environment in the ovary can influence the development of EOC (7).

Gonadotropins, including luteinizing hormone (LH) and follicle stimulating hormone (FSH), are conducive to the growth of ovarian cancer based on the 'gonadotropin theory' (5) and are regulated by gonadotropin-releasing hormone $(\mathrm{GnRH})$. GnRH agonists initially stimulate the release of gonadotropins, while sustained administration inhibits the release by desensitizing or downregulating the expression of the GnRH receptor (GnRHR). Clinically, GnRH agonists have been widely used in the treatment of hormonedependent tumors, such as breast (8) and prostate cancer (9). GnRH and GnRH agonists are involved in the regulation of proliferation, apoptosis and other biological behaviors of ovarian cancer cells $(10,11)$. Previous studies, including ours, have revealed that GnRH agonists inhibit the growth and proliferation of ovarian cancer through GnRHR (10,12-14), indicating that GnRH agonists and the GnRHR may be used as antitumor strategies in the future (15).

However, the effect of GnRH agonists on the apoptosis of EOC cells and their molecular mechanisms remain largely unidentified. In this study, we aimed to investigate the 
biological function of goserelin and the underlying mechanisms involving goserelin and EOC apoptosis using in vitro and in vivo experiments. The present study will facilitate a better understanding of the mechanisms underlying the effect of GnRH agonists on EOC. Meanwhile, key factors in the regulatory pathways may provide new therapeutic targets for the treatment of EOC.

\section{Materials and methods}

Cell lines and reagents. The human EOC cell lines (SKOV3, SKOV3-ip and A2780) were kindly provided by the University of Texas MD Anderson Cancer Center (Houston, TX, USA) and were authenticated by Short Tandem Repeat (STR) profiling. All cells were cultured in RPMI-1640 medium with $10 \%$ fetal bovine serum (FBS) (both from Gibco, Grand Island, NY, USA) and $100 \mathrm{U} / \mathrm{ml}$ penicillin, $100 \mathrm{mg} / \mathrm{ml}$ streptomycin at $5 \% \mathrm{CO}_{2}$ in a $37^{\circ} \mathrm{C}$ humidified atmosphere. The $\mathrm{GnRH}$ agonist goserelin acetate was purchased from Sigma-Aldrich (St. Louis, MO, USA) and dissolved in phosphate-buffered solution (PBS, in vitro) or normal saline (NS, in vivo).

Goserelin stimulation. Monoplast suspensions of SKOV3, SKOV3-ip or A2780 cells were seeded into 6-well plates at a density of $2 \times 10^{5}$ cells $/ \mathrm{ml}$ and a total volume of $2 \mathrm{ml}$. Twentyfour hours later, EOC cells were starved in FBS-free medium for $18 \mathrm{~h}$. Then, the cells were stimulated with different concentrations $\left(10^{-9}, 10^{-8}, 10^{-7}, 10^{-6}, 10^{-5}, 10^{-4}\right.$ or $\left.10^{-3} \mathrm{~mol} / \mathrm{l}\right)$ of goserelin (for the flow cytometry) or $10^{-4} \mathrm{~mol} / 1$ goserelin (for apoptosis assay, human apoptosis gene PCR array, qRT-PCR and the relative protein assay) for different time courses. PBS was used as a control. The transfected cells were also starved for $18 \mathrm{~h}$ and then stimulated with $10^{-4} \mathrm{~mol} / 1$ goserelin for another $48 \mathrm{~h}$. The cells were harvested and used for flow cytometry; meanwhile the protein or mRNA were extracted for western blot or qRT-PCR analyses.

Apoptosis assay. Apoptotic cells were identified by Annexin V-PE Apoptosis Detection kit (BD Biosciences, Franklin Lakes, NJ, USA) or the Hoechst staining kit (Beyotime Institute of Biotechnology, Shanghai, China) according to the manufacturer's instructions. EOC cells were starved in FBS-free medium for $18 \mathrm{~h}$ before treatment with goserelin or PBS. After incubating for the indicated periods of time, the cells were harvested and washed twice with cold PBS and resuspended in binding buffer at a concentration of $1 \times 10^{6}$ cell $/ \mathrm{ml}$. PE Annexin V (5 $\left.\mu \mathrm{l}\right)$ and 7-AAD (5 $\left.\mu \mathrm{l}\right)$ were added and then incubation was carried out for $15 \mathrm{~min}$ in the dark. A flow cytometer and FlowJo software (Flowjo LLC, Ashland, OR, USA) were used to analyze the staining data. Meanwhile, following the corresponding treatment, cells incubated in 6-well plates were stained with Hoechst staining at room temperature in the dark for $5 \mathrm{~min}$ and subsequently observed under confocal microscopy (Leica Microsystems, Wetzlar, Germany) with an excitation wavelength of $350 \mathrm{~nm}$ and an emission wavelength of $460 \mathrm{~nm}$.

Western blotting. Cells were harvested in RIPA lysis buffer containing PMSF and phosphatase inhibitor (Sangon Biotech Co., Ltd., Shanghai, China) and the protein concentration
Table I. siRNAs used in the study.

\begin{tabular}{ll}
\hline Name & \multicolumn{1}{c}{ Sequence } \\
\hline FOXO1-siRNA-1 & 5'-CCCUCGAACUAGCUAAAUTT-3' \\
& 5'-CCCUCGAACUAGCUAAAUTT-3' \\
FOXO1-siRNA-2 & 5'-CCCAGUCUGUCUGAGAUAATT-3' \\
& 5'-UUAUCUCAGACAGACUGGGTT-3' \\
AKT-siRNA-1: & 5'-AGGAAGUCAUCGUGGCCAATT-3' \\
& 5'-UUGGCCACGAUGACUUCCUTT-3' \\
AKT-siRNA-2 & 5'-GCACUUUCGGCAAGGUGAUTT-3' \\
& 5'-AUCACCUUGCCGAAAGUGCTT-3' \\
\hline
\end{tabular}

was quantified using a BCA assay kit (Beyotime Institute of Biotechnology). Equal amounts of protein (40 $\mu \mathrm{g} / \mathrm{lane})$ were separated on SDS-PAGE gels and transferred to PVDF membranes. The membranes were blocked with $5 \%$ non-fat milk for $1 \mathrm{~h}$ and incubated with primary antibodies at $4^{\circ} \mathrm{C}$ overnight. After incubating with an HRP-conjugated secondary antibody, the bands were visualized using an ECL detection system (Thermo Fisher Scientific, Waltham, MA, USA). Antibodies including rabbit anti-cleaved-caspase-3 monoclonal antibody (cat. no. 9664, 1:1,000), rabbit anti-p-AKT (Ser473) monoclonal antibody (cat. no. 4060, 1:1,000), rabbit anti-AKT monoclonal antibody (cat. no. 4691, 1:1,000), rabbit anti-FOXO1 monoclonal antibody (cat. no. 2880, 1:1,000), rabbit anti-BIK polyclonal antibody (cat. no. 4592, 1:1,000) and rabbit anti-TNFRSF9 polyclonal antibody (cat. no. 62634, 1:1,000) were purchased from Cell Signaling Technology (Danvers, MA, USA). Rabbit anti-GnRHR polyclonal antibody (cat. no. ab183079, 1:1,000), rabbit anti-cleaved-PARP monoclonal antibody (cat. no. ab32064, 1:1,000) and rabbit anti-CIDEA polyclonal antibody (cat. no. ab151577, 1:1,000) were purchased from Abcam (Cambridge, UK).

siRNA and cell transfection. siRNAs were designed and purchased from Shanghai GenePharma Co., Ltd., Technology (Shanghai, China) and are listed in Table I. FOXO1-siRNA, AKT-siRNA and scrambled siRNA were transfected into cells using Lipofectamine 2000 (Invitrogen, Carlsbad, CA, USA) according to the manufacturer's protocol. Briefly, $2 \times 10^{5}$ SKOV3-ip cells/well were seeded into 6-well plates for $24 \mathrm{~h}$ when the cells had reached $40-50 \%$ confluence. Before transfection, the RPMI-1640 medium without FBS and antibiotics were replaced. A total of siRNA (75 pmol) and $5 \mu \mathrm{l}$ of Lipofectamine 2000 were diluted in $125 \mu \mathrm{l} \mathrm{Opti-MEM}$ and incubated for $5 \mathrm{~min}$ at room temperature, respectively. The diluted siRNA and diluted Lipofectamine 2000 were mixed gently and incubated for $20 \mathrm{~min}$. A total of $250 \mu \mathrm{l}$ mixed-combination was added to each well in a final volume of $2 \mathrm{ml} /$ well.

Human apoptosis gene PCR array and $q R T-P C R$. SKOV3-ip cells were starved in FBS-free medium for $18 \mathrm{~h}$ before treatment with goserelin or PBS. After $48 \mathrm{~h}$ of incubation, total RNA was extracted using an RNeasy ${ }^{\circledR}$ Mini kit (Qiagen, Hilden, Germany) and then converted into cDNA using an $\mathrm{RT}^{2}$ First Strand kit (Qiagen) following the manufacturer's instructions. 
Table II. The primers used in the study.

\begin{tabular}{|c|c|c|}
\hline Gene & Primer & Sequence (5'-3') \\
\hline X & $\begin{array}{l}\text { Forward } \\
\text { Reverse }\end{array}$ & $\begin{array}{l}\text { CGGGTATGTAACTGAACTTG } \\
\text { GCTGTAGTTGCCTCTTTAAT }\end{array}$ \\
\hline AKT1 & $\begin{array}{l}\text { Forward } \\
\text { Reverse }\end{array}$ & $\begin{array}{l}\text { CTTCAAGCCCCAGGTCAC } \\
\text { CGCTGTCCACACACTCCAT }\end{array}$ \\
\hline GAPDH & $\begin{array}{l}\text { Forward } \\
\text { Reverse }\end{array}$ & $\begin{array}{l}\text { ACCACAGTCCATGCCATCAC } \\
\text { CCACCACCCTGTTGCTGTAG }\end{array}$ \\
\hline BCL2L10 & $\begin{array}{l}\text { Forward } \\
\text { Reverse }\end{array}$ & $\begin{array}{l}\text { GGATTCCGTGCTCTCCGACA } \\
\text { TCGCCCTCCTGCTCCTTTAG }\end{array}$ \\
\hline BIK & $\begin{array}{l}\text { Forward } \\
\text { Reverse }\end{array}$ & $\begin{array}{l}\text { GGAGGTTCTTGGCATGACTGA } \\
\text { GCTCACGTCCATCTCGTCC }\end{array}$ \\
\hline CASP14 & $\begin{array}{l}\text { Forward } \\
\text { Reverse }\end{array}$ & $\begin{array}{l}\text { CCACGGTAGAGGGATACATCG } \\
\text { GAGGGTGCTTTGGATTTCAGG }\end{array}$ \\
\hline FASLG & $\begin{array}{l}\text { Forward } \\
\text { Reverse }\end{array}$ & $\begin{array}{l}\text { CTTCCCTGTCCAACCTCTGTG } \\
\text { CTACCAAGGCAACCAGAACCA }\end{array}$ \\
\hline IL10 & $\begin{array}{l}\text { Forward } \\
\text { Reverse }\end{array}$ & $\begin{array}{l}\text { AAGCTGAGAACCAAGACCCAG } \\
\text { ATCGATGACAGCGCCGTAG }\end{array}$ \\
\hline PYCARD & $\begin{array}{l}\text { Forward } \\
\text { Reverse }\end{array}$ & $\begin{array}{l}\text { TTGGACCTCACCGACAAGC } \\
\text { ATGTCGCGCAGCACGTTA }\end{array}$ \\
\hline TNFRSF1B & $\begin{array}{l}\text { Forward } \\
\text { Reverse }\end{array}$ & $\begin{array}{l}\text { CACCGGGAGCTCAGATTCTTC } \\
\text { CACTGTGAGCTGTGGTCAGA }\end{array}$ \\
\hline TNFSF8 & $\begin{array}{l}\text { Forward } \\
\text { Reverse }\end{array}$ & $\begin{array}{l}\text { TGTTGGTCGTTCAGAGGACG } \\
\text { TGGAGGTAGGCCCATGACTT }\end{array}$ \\
\hline TP73 & $\begin{array}{l}\text { Forward } \\
\text { Reverse }\end{array}$ & $\begin{array}{l}\text { GGAGGGACTTCAACGAAGGA } \\
\text { GGGTCATCCACATACTGCGA }\end{array}$ \\
\hline
\end{tabular}

Apoptosis-associated gene expression profiles were evaluated using RT $^{2}$ Profiler $^{\mathrm{TM}}$ PCR Arrays (Qiagen), which assess 84 genes involved in different apoptosis pathways. In addition, qRT-PCR was performed to confirm the differential expression of apoptosis-related genes using the ABI 7000 Real-Time PCR system (Applied Biosystems, Foster City, CA, USA) with an RT-PCR kit (Takara Bio, Shiga, Japan) according to the manufacturer's protocol. The primers (Sangon Biotech) used in qRT-PCR are listed in Table II. The PCR conditions included an initial denaturation step at $95^{\circ} \mathrm{C}$ for $10 \mathrm{~min}$ and 45 cycles of $95^{\circ} \mathrm{C}$ for $5 \mathrm{sec}$ and $60^{\circ} \mathrm{C}$ for $30 \mathrm{sec}$. All the experiments were performed in triplicate, and all the samples were normalized to $\beta$-actin expression. The expression fold changes were calculated using the $2^{-\Delta \Delta \mathrm{Ct}}$ method.

In vivo study. Five-week-old specific-pathogen free (SPF) female nude mice, weighing 18-20 g, were purchased from Shanghai SLAC Laboratory Animal Corporation. The mice were cared for in accordance with the criteria of the Medical Laboratory Animal Administrative Committee of Shanghai and the Guide for the Care and Use of Laboratory Animals. All experimental procedures were approved by the Ethics Committee of Obstetrics and Gynecology Hospital of Fudan University.
SKOV3 $\left(1 \times 10^{7} / \mathrm{ml}\right)$ cells were heterotransplanted into 14 nude mice, 6 of which were injected with SKOV3 cells labelled with CM-DiI (Invitrogen). Six CM-DiI-labelled nude mice and the other 8 nude mice were divided randomly into 2 groups respectively: the Goserelin group was subcutaneously injected daily with $100 \mu \mathrm{g}$ of goserelin in $200 \mu \mathrm{l}$ of NS $(14,16,17)$; the NS group was subcutaneously injected with $200 \mu$ l of NS per day. Subcutaneous xenograft tumors in nude mice were monitored by an in vivo imaging system. After 19 days of treatment, the mice were sacrificed, and the xenograft tumors were fixed in $4 \%$ paraformaldehyde for immunohistochemistry and TUNEL staining. The weights of the nude mice, TUNEL staining and immunohistochemical staining for FOXO1, AKT/p-AKT and GnRHR expression in the xenograft tumors were compared between the two groups.

CM-DiI for long-term cellular labeling. Stock solutions of CM-DiI were prepared in DMSO at $1 \mathrm{mg} / \mathrm{ml}$. SKOV3 cells were harvested and washed twice with PBS and resuspended in PBS at a concentration of $1 \times 10^{6}$ cells $/ \mathrm{ml}$. An appropriate $1 \mathrm{mg} / \mathrm{ml}$ stock solution was added into the cell suspension at a $1 \mu \mathrm{g} / \mathrm{ml}$ final working concentration and incubated for $6 \mathrm{~min}$ at $37^{\circ} \mathrm{C}$ and then for an additional $15 \mathrm{~min}$ at $4^{\circ} \mathrm{C}$. Labelled SKOV3 cells were washed twice with PBS again and resuspended in PBS at a concentration of $1 \times 10^{7}$ cells $/ \mathrm{ml}$. A drop of labelled SKOV3 cells was placed on a slide and the efficiency of cell labelling was determined to be $98 \%$ under a fluorescence microscope.

Immunohistochemistry (IHC) and TUNEL staining. The xenograft tumors were fixed in $4 \%$ paraformaldehyde and dehydrated through a serial alcohol gradient and then embedded in paraffin. After sectioning (5- $\mu \mathrm{m}$ thick), the tissues were immunostained with anti-FOXO1 (1:50), anti-AKT (1:200), anti-p-AKT (1:50) and anti-GnRHR (1:300) antibodies using a Histostain-Plus IHC kit (NeoBioscience, Shanghai, China) and subjected to TUNEL staining using a TUNEL Apoptosis Assay kit (Roche Diagnostics, Indianapolis, IN, USA) following the manufacturer's protocol. The immunostaining was evaluated by determining the immunoreactive score (IRS). The IRS was calculated by multiplying the staining intensity (SI) by the percentage of positive cells (PP). SI was defined as 0 (negative), 1 (weak), 2 (moderate) and 3 (strong). PP was defined as 0 (negative), 1 ( $\leq 10 \%$ positive cells), 2 (11-50\% positive cells), 3 (51-75\% positive cells) and 4 (>75\% positive cells). IRS $=$ SI $x$ PP, and an IRS $>3$ was defined as positive (18).

Statistical analysis. Stata 14.0 (StataCorp LP, College Station, TX, USA) and GraphPad Prism 6.0 (GraphPad Software Inc., La Jolla, CA, USA) were used for the statistical analyses. Continuous data are expressed as the mean $\pm \mathrm{SD}$, and analyzed by independent t-test between two groups or one-way ANOVA among multiple groups. The categorical data were compared using the Chi-squared or Fisher's exact tests as appropriate. Differences were considered statistically significant at $\mathrm{P}<0.05$.

\section{Results}

Goserelin promotes the apoptosis of EOC cells in vitro. SKOV3, SKOV3-ip and A2780 cells all expressed GnRHR 


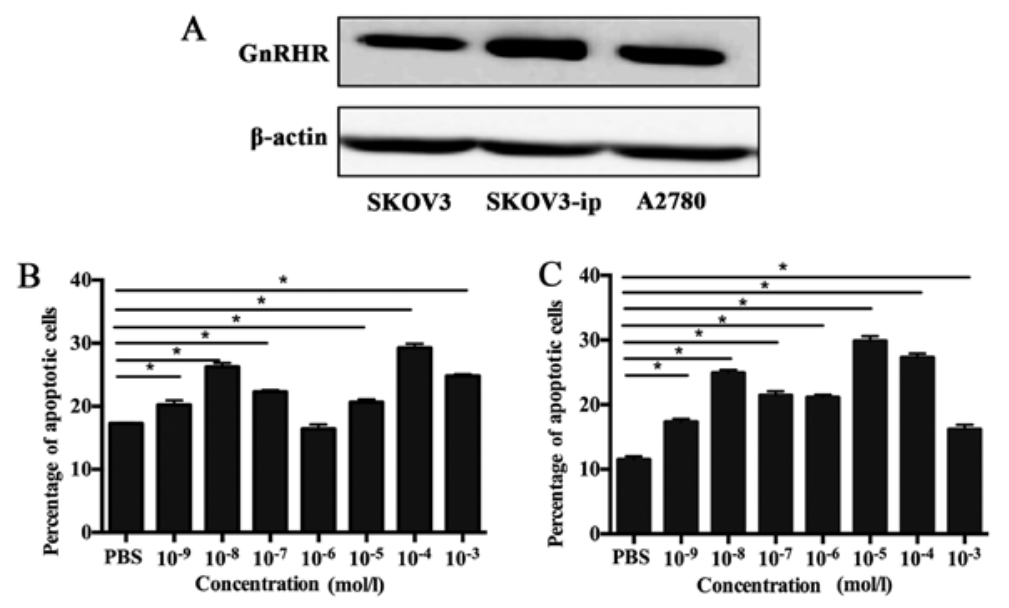

Figure 1. GnRHR expression in EOC cells and the pro-apoptotic effect by different concentrations of goserelin at different time-points. (A) Western blot analysis of GnRHR expression in SKOV3, SKOV3-ip and A2780 cells. Flow cytometric analysis of total apoptosis rate of SKOV3-ip cells after treatment with goserelin for 48 (B) and $72 \mathrm{~h}(\mathrm{C}) .{ }^{*} \mathrm{P}<0.05$, one-way ANOVA was performed for comparisons between goserelin and PBS group.

A
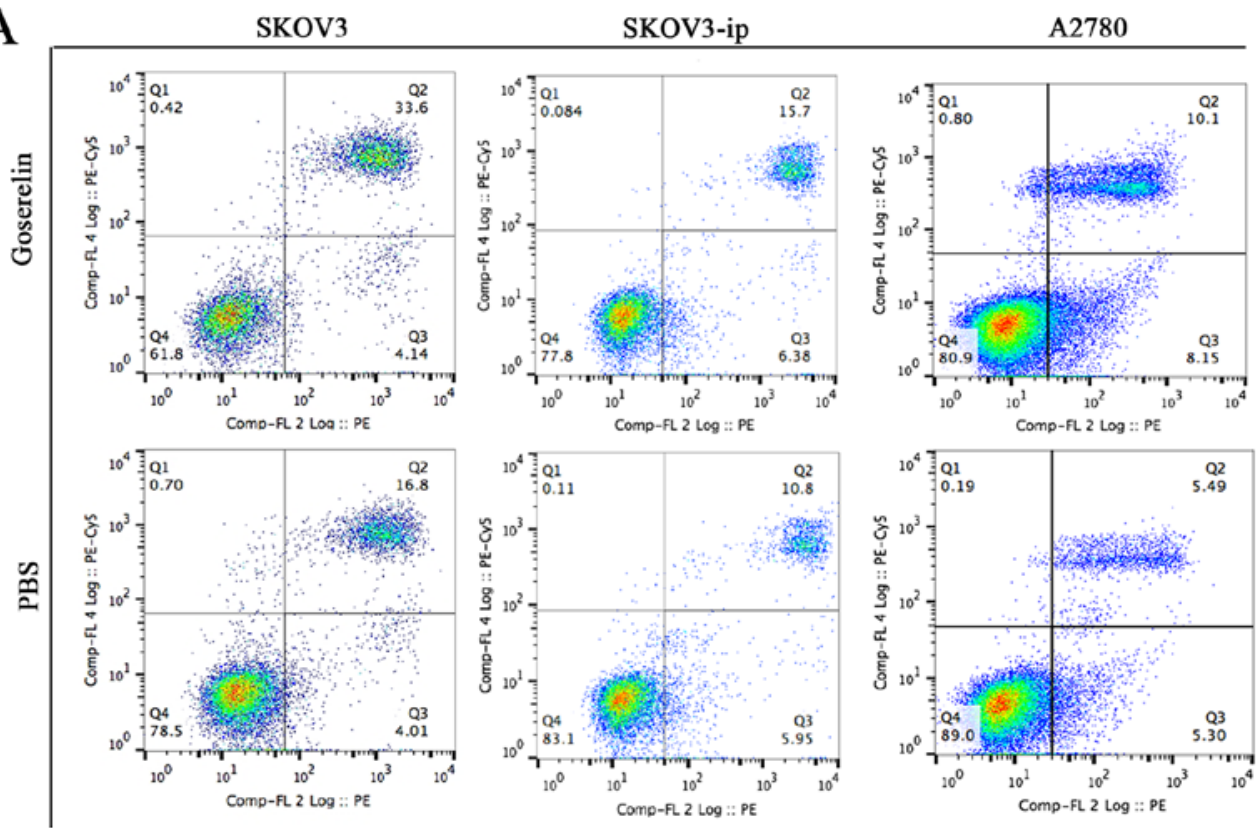

B
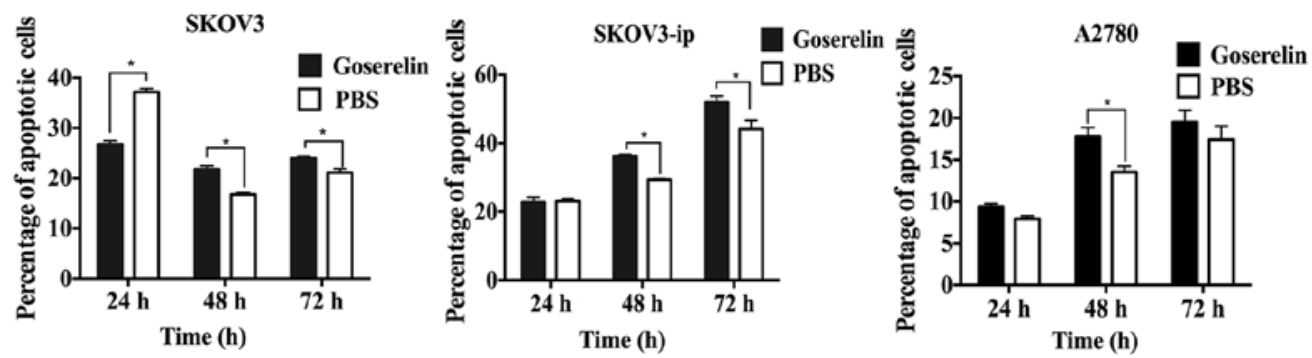

Figure 2. Flow cytometric analysis of pro-apoptotic effect by goserelin on EOC cells. Representative dot plots (for $48 \mathrm{~h}$ ) (A) and quantification (B) of apoptotic cells after treatment with $10^{-4} \mathrm{~mol} / 1$ goserelin at different time-points in SKOV3, SKOV3-ip and A2780 cells. "P<0.05, t-tests were performed for comparisons between goserelin and PBS group.

(Fig. 1A). Apoptosis detected by flow cytometry showed that different concentrations of goserelin increased the proportion of apoptotic SKOV3-ip cells compared with the control group at 48 and $72 \mathrm{~h}(\mathrm{P}<0.05$; Fig. $1 \mathrm{~B}$ and $\mathrm{C})$. A concentration of $10^{-4} \mathrm{~mol} / \mathrm{l}$ goserelin significantly increased the total apoptosis rate of SKOV3-ip, SKOV3 and A2780 cells ( $\mathrm{P}<0.05$; Fig. 2A and $\mathrm{B})$. To further clarify the effect of goserelin on apoptosis, we treated the cells with $10^{-4} \mathrm{~mol} / 1$ goserelin for 24, 48 and $72 \mathrm{~h}$. Hoechst staining showed that the number of apoptotic bodies was significantly increased in the SKOV3 and SKOV3-ip cells compared with the control group $(\mathrm{P}<0.05$; Fig. 3). Furthermore, the expression 


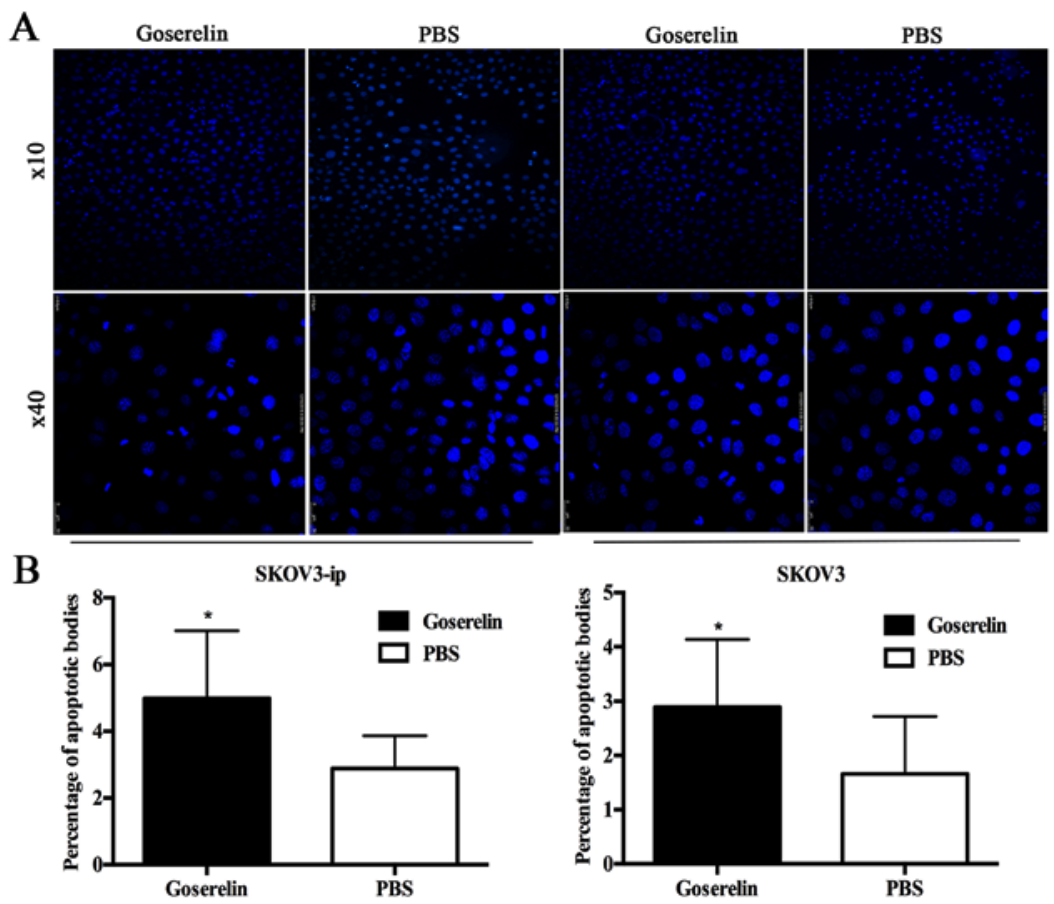

Figure 3. Hoechst staining analysis of the pro-apoptotic effect by goserelin on EOC cells. Representative micrographs (A) and quantification (B) of apoptotic bodies after treatment with $10^{-4} \mathrm{~mol} / 1$ goserelin for $48 \mathrm{~h}$ in SKOV3-ip and SKOV3 cells. (A) x10 (upper panel) and x40 (lower panel) original magnification. ${ }^{*} \mathrm{P}<0.05$, t-tests were performed for comparisons between goserelin and PBS group.

A

SKOV3-ip

SKOV3

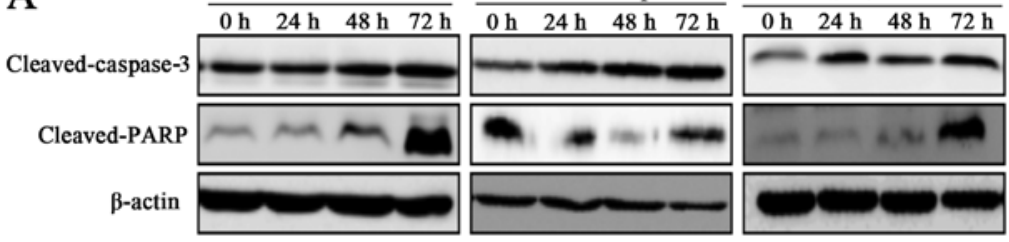

B
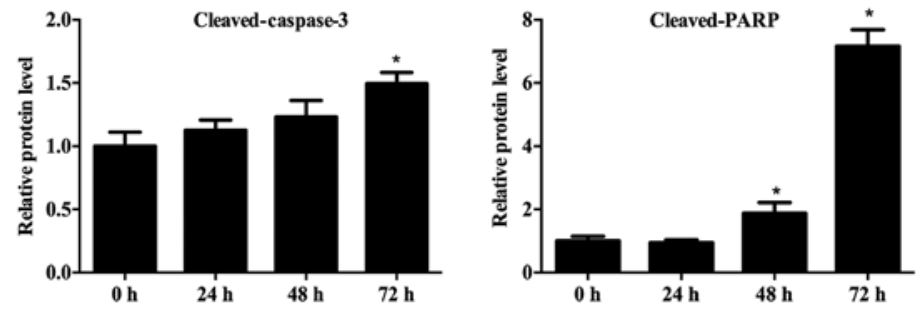

$\mathrm{C}$
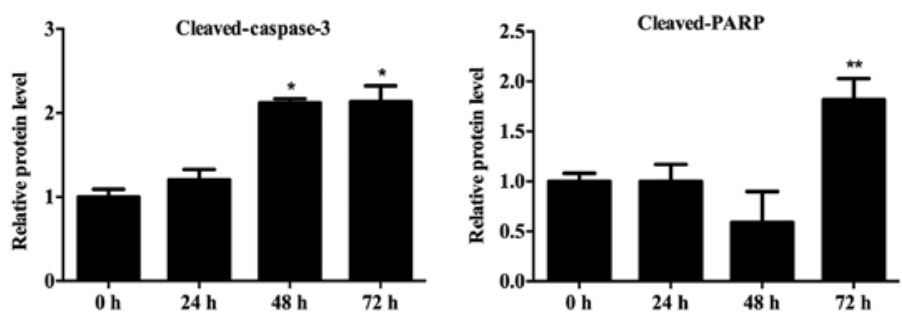

D
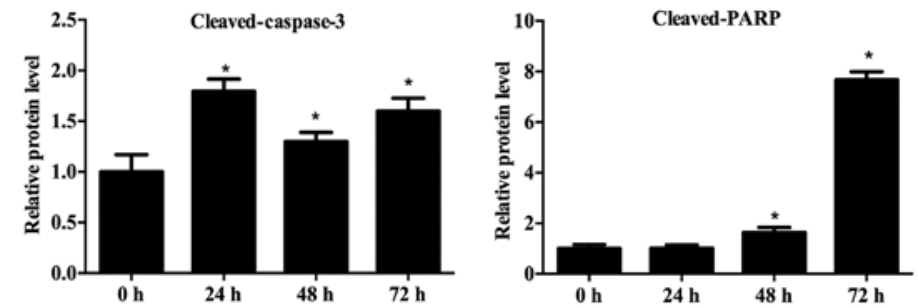

Figure 4. (A-D) Western blot analysis of cleaved-caspase-3 and cleaved-PARP expression after treatment with 10-4 mol/1 goserelin in A2780 (B), SKOV3-ip (C) and SKOV3 (D) cells at different time-points. "P<0.05, one-way ANOVA was performed for comparisons between goserelin and PBS group. 
Table III. Nine differentially expressed genes (fold change $\geq 1.5$ ) were screened in the SKOV3-ip-Goserelin group.

\begin{tabular}{lllr}
\hline Gene name & GeneBank ID & \multicolumn{1}{c}{ Description } & Fold change \\
\hline BCL2L10 & NM_020396 & BCL2-like 10 (apoptosis facilitator) & -1.53 \\
BIK & NM_001197 & BCL2-interacting killer (apoptosis-inducing) & 2.38 \\
CASP14 & NM_012114 & Caspase-14, apoptosis-related cysteine peptidase & 1.67 \\
FASLG & NM_000639 & Fas ligand (TNF superfamily, member 6) & -4.49 \\
IL10 & NM_000572 & Interleukin 10 & -2.39 \\
PYCARD & NM_013258 & PYD and CARD domain containing & 1.6 \\
TNFRSF1B & TNFRSF1B & Tumor necrosis factor receptor superfamily, member 1B \\
TNFSF8 & NM_001244 & Tumor necrosis factor (ligand) superfamily, member 8 & 1.67 \\
TP73 & NM_005427 & Tumor protein p73 & -1.93 \\
\hline
\end{tabular}

A

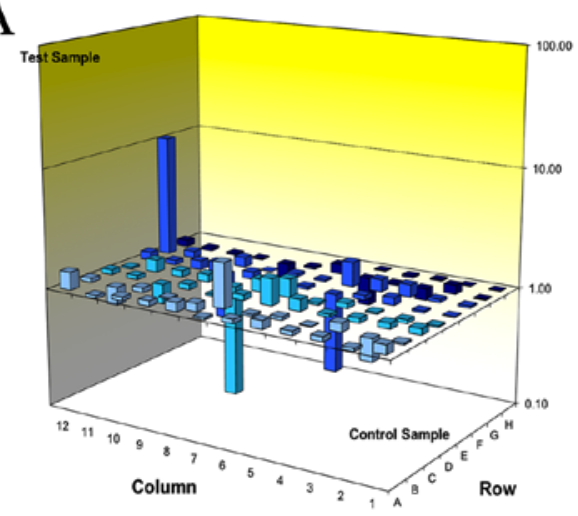

B

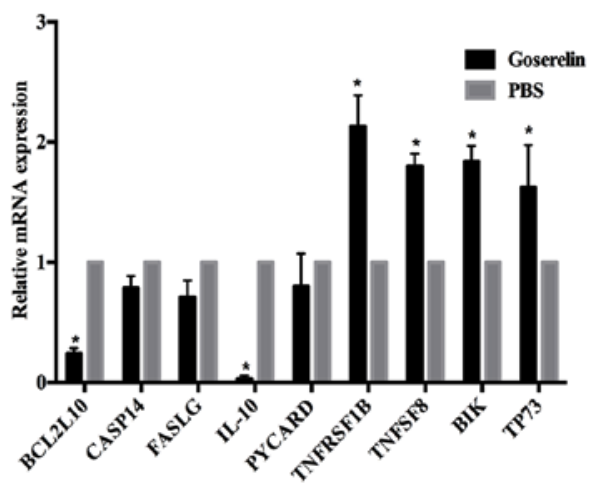

$\mathrm{C}$
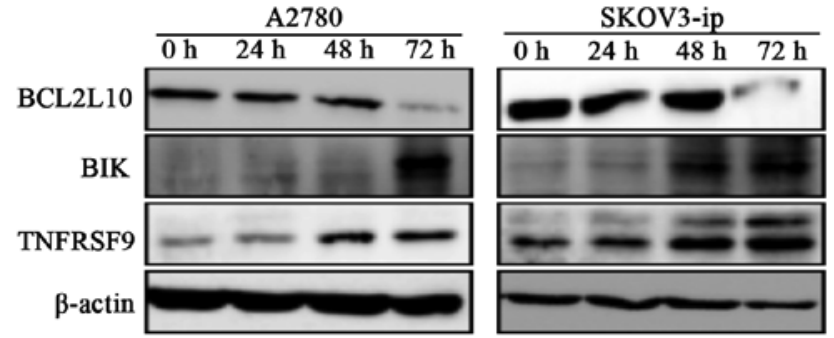

D

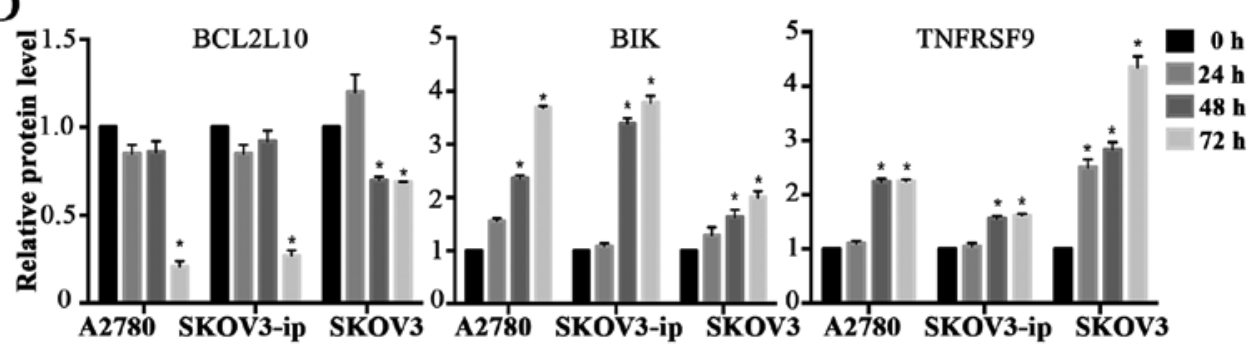

Figure 5. Expression of human apoptosis-related genes regulated by goserelin in SKOV3-ip cells. Human apoptosis gene PCR array (A), qRT-PCR (B), western blot analysis (C) and quantification (D) of western blot analyses of downstream molecular events involving goserelin and EOC cell apoptosis. * $\mathrm{P}<0.05$, $\mathrm{t}$-tests and one-way ANOVA were performed for comparisons between goserelin and PBS group.

of cleaved-caspase-3 and cleaved-PARP were observably increased after treatment with $10^{-4} \mathrm{~mol} / 1$ goserelin $(\mathrm{P}<0.05$; Fig. 4). Taken together, these results suggested that goserelin promoted EOC cell apoptosis.

Expression of human apoptosis-related genes is regulated by goserelin in SKOV3-ip cells. To investigate the downstream molecular process involving goserelin and EOC apoptosis, human apoptosis gene PCR arrays were tested in the SKOV3ip-PBS and SKOV3-ip-Goserelin group. According to the apoptosis gene PCR array, 9 genes were obviously expressed (fold change $\geq 1.5$ ) in the SKOV3-ip-Goserelin group compared with the SKOV3-ip-PBS group (Table III). qRT-PCR and western blot analyses were performed to confirm the expression of these genes, including members of the tumor necrosis factor (TNF) and TNF receptor superfamilies (such as TNFRSF9, 


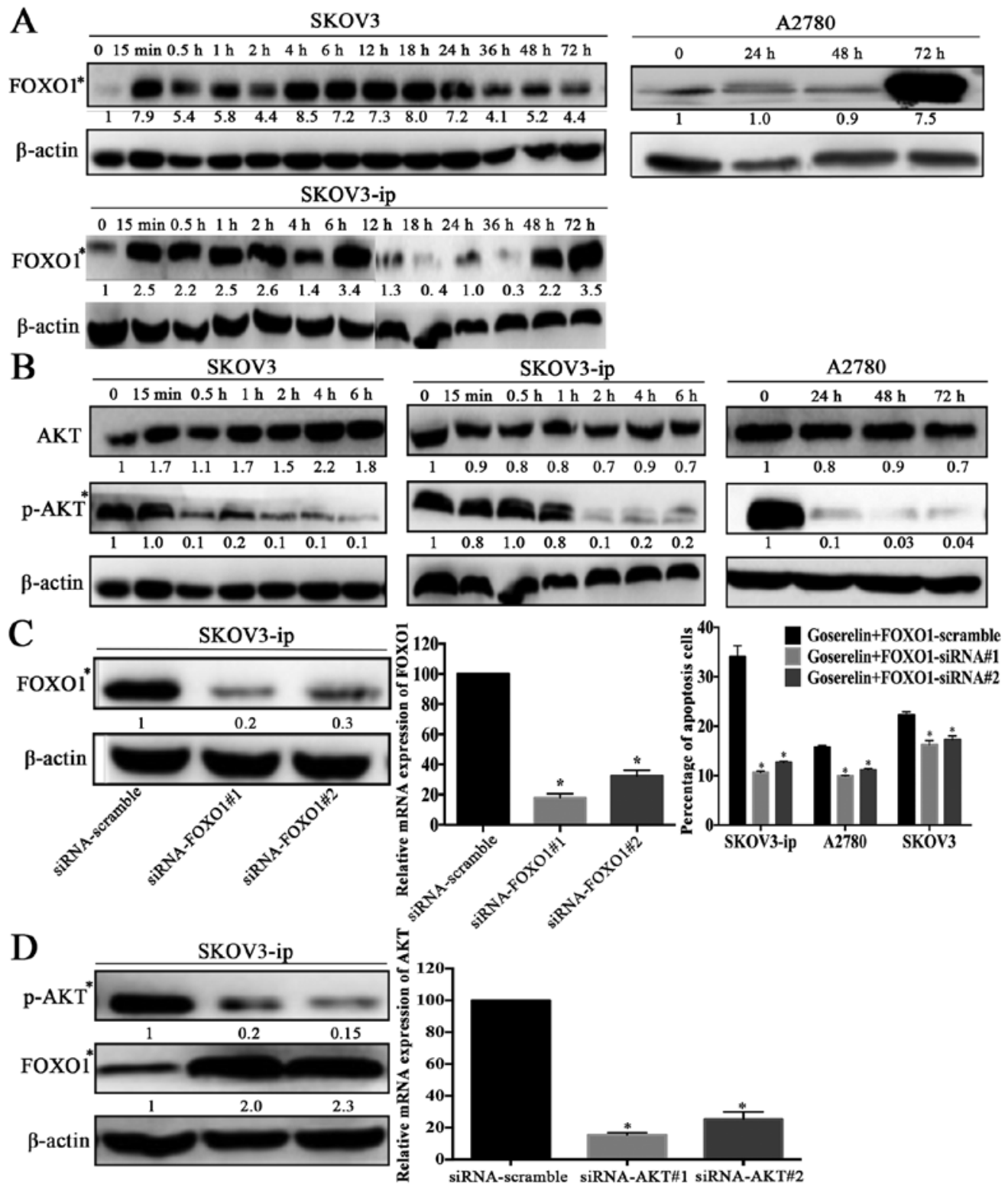

Figure 6. Goserelin upregulates FOXO1 through the PI3K/AKT signaling pathway. Western blot analysis of FOXO1 (A), AKT and p-AKT (B) expression in SKOV3-ip, SKOV3 and A2780 cells after treatment with $10^{-4} \mathrm{~mol} / \mathrm{l}$ goserelin at different time-points. (C) Flow cytometric analysis showed that the promotion of apoptosis by goserelin was abrogated (right panel) by FOXO1-siRNA (left and middle panel). (D) Western blot analysis showed that the expression of FOXO1 was increased (left panel) by AKT-siRNA (right panel). ${ }^{*}<0.05$, one-way ANOVA was performed for comparisons between goserelin and PBS group; $\mathrm{t}$-tests were performed for comparisons between siRNA and scramble group.

TNFRSF1B and TNFSF8). The results were mostly consistent with those of the PCR array analysis (Fig. 5A-D).

Goserelin influences EOC cell apoptosis by upregulating FOXO1 through the PI3K/AKT signaling pathway. TNF and TNF receptors are reportedly regulated by FOXO1 (19). We then detected the expression of FOXO1 by goserelin at $10^{-4} \mathrm{~mol} / 1$. As shown in Fig. 6A, FOXO1 expression was significantly increased $(\mathrm{P}<0.05)$ and the goserelin-mediated promotion of apoptosis was abrogated by FOXO1-siRNA ( $\mathrm{P}<0.05$; Fig. 6C).

As FOXO1 is a downstream target of the PI3K/AKT signaling pathway $(20,21)$, the expression of AKT/p-AKT was analyzed. As shown in Fig. 6B, goserelin downregulated p-AKT (Ser473) expression. Meanwhile, the expression of FOXO1 was increased by AKT-siRNA ( $<<0.05$; Fig. 6D). Taken together, these data suggest that goserelin may promote
EOC cell apoptosis by upregulating FOXO1 through the PI3K/AKT signaling pathway.

Effect of goserelin on subcutaneous xenograft tumors in nude mice. In vivo images of subcutaneous xenograft tumors in nude mice revealed that the subcutaneous xenograft tumor model was constructed successfully (Fig. 7A). TUNEL staining showed that goserelin significantly increased the proportion of apoptotic cells in the subcutaneous xenograft tumors $(\mathrm{P}<0.05$; Fig. $7 \mathrm{~B}$ and $\mathrm{C})$. Immunohistochemistry results showed that the difference in AKT expression between the two groups was not significant. In the goserelin group, p-AKT expression was significantly lower, while the expression of FOXO1 and GnRHR were significantly increased compared with the NS group $(\mathrm{P}<0.05$; Fig. 7B and D). Therefore, the expression of the key factors in the PI3K/ AKT-FOXO1 pathway was consistent with that observed in vitro. 
A

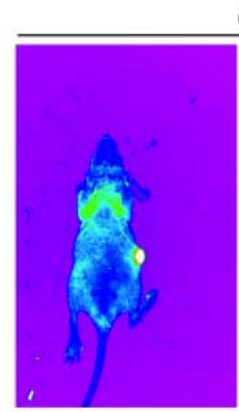

Goserelin

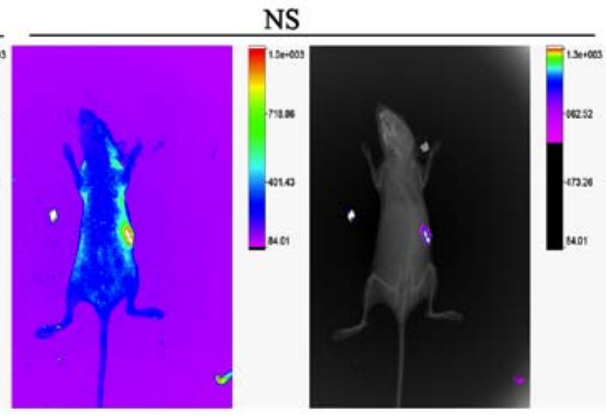

B

B TUNEL
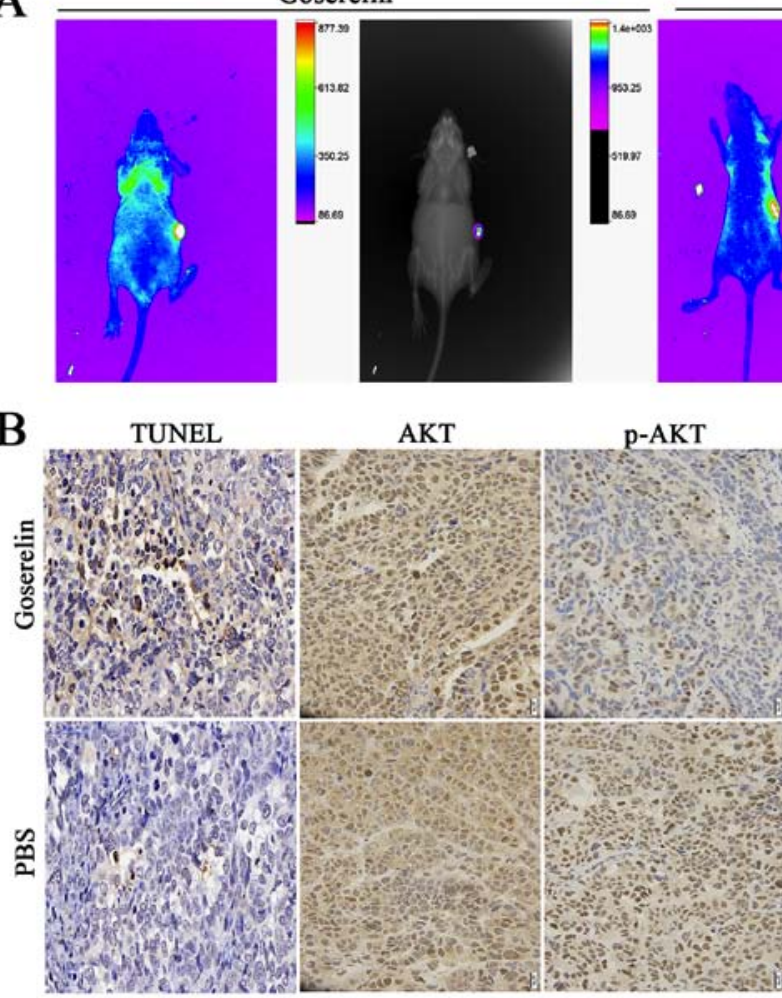

GnRHR

C

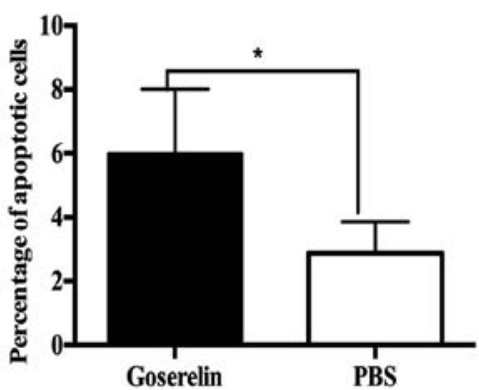

D

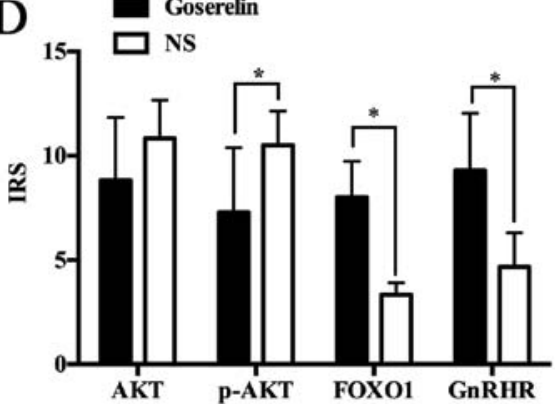

Figure 7. Effect of goserelin on subcutaneous xenograft tumors in nude mice. (A) Representative in vivo images of subcutaneous xenograft tumors in nude mice after 7 days of treatment. (B) TUNEL staining and immunohistochemistry analysis of AKT, p-AKT, FOXO1 and GnRHR protein expression in the goserelin and NS groups. Original magnification, $\mathrm{x} 40$. Quantification of apoptotic cells (C) and the IRS (D) between two groups. *P<0.05, t-tests were performed for comparisons between goserelin and NS group.

\section{Discussion}

According to the gonadotropin theory (5), gonadotropins, including $\mathrm{LH}$ and FSH, are conducive to the growth of ovarian cancer, which can be downregulated by $\mathrm{GnRH}$ agonists. Theoretically, GnRH agonists inhibit the growth and proliferation of ovarian cancer. Several studies, including ours, have revealed that GnRH agonists can directly inhibit the growth and proliferation of various human cancer cell lines, including ovarian cancer cell lines, through the GnRHR in a dose- and time-dependent manner (8-10,12-14). In the present study, we demonstrated that SKOV3, SKOV3-ip and A2780 cells all expressed GnRHR, which may be required for goserelin to act on these three cell lines. We found that goserelin promoted EOC cell apoptosis, which was verified by different methods in three EOC cell lines. In vivo, goserelin also promoted the apoptosis of xenograft tumors. Considering its less adverse side-effects compared with chemotherapeutic drugs, goserelin may be a safe and effective antitumor strategy in the future.
It has been reported that the apoptosis of human ovarian cancer cells may be regulated by goserelin $(13,22)$. We used human apoptosis gene PCR array to explore the downstream molecular events involving goserelin and EOC apoptosis. Goserelin regulated several apoptosis-related factors, especially members of the TNF and TNF receptor superfamilies, which are regulated by FOXO1 (19). The FOXO transcription factors are considered to be tumor suppressors that inhibit cell proliferation and induce apoptosis (21). Indeed, FOXO1 plays multiple roles in various types of human cancers, including skin (23), liver (24) and breast cancer (25). An increasing number of studies have linked the tumor suppressor activity of FOXOs to the regulation of genes involved in cell death (e.g., Fasl) (26) and cell cycle arrest (e.g., p27 ${ }^{\mathrm{KIPl}}$ ) (27). In agreement with these reports, we found that goserelin increased FOXO1 expression. Meanwhile, the pro-apoptotic effect of goserelin was abrogated by FOXO1-siRNA. These results indicate that goserelin induces EOC cell apoptosis by modulating FOXO1 activity. 
It has been reported that AKT phosphorylation following growth factor stimulation can lead to FOXO inactivation (28). In breast cancer cell lines, the targeted depletion of PI3K using siRNA reactivates FOXO1, 3 and 4, which then induces cell cycle arrest and apoptosis (29). The same anti-proliferation and pro-apoptotic effects were observed when FOXO1 was reactivated in cervical cancer treated with the PI3K inhibitor LY294002 (30). We hypothesized that goserelin may promote EOC cell apoptosis by upregulating FOXO1 through the PI3K/AKT signaling pathway. As expected, goserelin downregulated p-AKT expression, and FOXO1 upregulation was dependent on PI3K/AKT. The mechanism by which goserelin activates the AKT signaling pathway requires further exploration. In vivo, the expression of key factors in the PI3K/AKT-FOXO1 pathway was consistent with that observed in vitro. Importantly, GnRHR expression in the goserelin group increased significantly, indicating that goserelin may exert its biological effects through the GnRHR.

In summary, our results demonstrated the pro-apoptotic effects of goserelin on EOC cells and showed for the first time that goserelin may promote EOC cell apoptosis by upregulating FOXO1 through the PI3K/AKT signaling pathway. PI3K/AKT-FOXO1 pathway may be the novel therapeutic target for the treatment of EOC. GnRH agonists may also be potential antitumor agents.

\section{Acknowledgements}

The present study was supported by the Youth National Natural Science Foundation of China (NSFC no. 81402152).

\section{References}

1. Hemminki K, Sundquist J and Brandt A: Incidence and mortality in epithelial ovarian cancer by family history of any cancer. Cancer 117: 3972-3980, 2011

2. Rustin G, van der Burg M, Griffin C, Qian W and Swart AM: Early versus delayed treatment of relapsed ovarian cancer. Lancet 377: 380-381, 2011.

3. Chen W, Zheng R, Baade PD, Zhang S, Zeng H, Bray F, Jemal A, $\mathrm{Yu}$ XQ and He J: Cancer statistics in China, 2015. CA Cancer J Clin 66: 115-132, 2016.

4. Casagrande JT, Louie EW, Pike MC, Roy S, Ross RK and Henderson BE: 'Incessant ovulation' and ovarian cancer. Lancet 2: 170-173, 1979.

5. Millar RP: GnRHs and GnRH receptors. Anim Reprod Sci 88: $5-28,2005$

6. Leung PC and Choi JH: Endocrine signaling in ovarian surface epithelium and cancer. Hum Reprod Update 13: 143-162, 2007.

7. Brekelmans CT: Risk factors and risk reduction of breast and ovarian cancer. Curr Opin Obstet Gynecol 15: 63-68, 2003.

8. Kim HJ, Yoon TI, Chae HD, Kim JE, Chae EY, Yu JH, Sohn G, Ko BS, Lee JW, Son BH, et al: Concurrent gonadotropinreleasing hormone agonist administration with chemotherapy improves neoadjuvant chemotherapy responses in young premenopausal breast cancer patients. J Breast Cancer 18: 365-370, 2015

9. Hoda MR, Kramer MW, Merseburger AS and Cronauer MV: Androgen deprivation therapy with Leuprolide acetate for treatment of advanced prostate cancer. Expert Opin Pharmacother 18: 105-113, 2017.

10. Zhang Z, Jia L, Feng Y and Zheng W: Overexpression of folliclestimulating hormone receptor facilitates the development of ovarian epithelial cancer. Cancer Lett 278: 56-64, 2009.
11. Zhang Z, Liao H, Chen X, Zheng Y, Liu Y, Tao X, Gu C, Dong L, Duan T, Yang Y, et al: Luteinizing hormone upregulates survivin and inhibits apoptosis in ovarian epithelial tumors. Eur J Obstet Gynecol Reprod Biol 155: 69-74, 2011.

12. So WK, Cheng JC, Poon SL and Leung PC: Gonadotropinreleasing hormone and ovarian cancer: A functional and mechanistic overview. FEBS J 275: 5496-5511, 2008.

13. Meyer C, Sims AH, Morgan K, Harrison B, Muir M, Bai J, Faratian D, Millar RP and Langdon SP: Transcript and protein profiling identifies signaling, growth arrest, apoptosis, and $\mathrm{NF}-\kappa \mathrm{B}$ survival signatures following GNRH receptor activation. Endocr Relat Cancer 20: 123-136, 2013.

14. Zhang Y, Ding JX, Tao X, Lu ZY, Wang JJ, Feng WW and Hua KQ: Goserelin can inhibit ovarian cancer proliferation and simultaneously protect ovarian function from cisplatin: An in vitro and in vivo study. J Chemother 25: 96-103, 2013.

15. Aguilar-Rojas A, Pérez-Solis MA and Maya-Núñez G: The gonadotropin-releasing hormone system: Perspectives from reproduction to cancer (Review). Int J Oncol 48: 861-868, 2016.

16. Yano T, Pinski J, Halmos G, Szepeshazi K, Groot K and Schally AV: Inhibition of growth of OV-1063 human epithelial ovarian cancer xenografts in nude mice by treatment with luteinizing hormone-releasing hormone antagonist SB-75. Proc Natl Acad Sci USA 91: 7090-7094, 1994.

17. Dondi D, Moretti RM, Montagnani Marelli M, Pratesi G, Polizzi D, Milani M, Motta M and Limonta P: Growth-inhibitory effects of luteinizing hormone-releasing hormone (LHRH) agonists on xenografts of the DU 145 human androgen-independent prostate cancer cell line in nude mice. Int J Cancer 76: 506-511, 1998.

18. Friedrichs K, Gluba S, Eidtmann $\mathrm{H}$ and Jonat W: Overexpression of p53 and prognosis in breast cancer. Cancer 72: 3641-3647, 1993.

19. van der Vos KE and Coffer PJ: The extending network of FOXO transcriptional target genes. Antioxid Redox Signal 14: 579-592, 2011.

20. Cardozo T and Pagano M: The SCF ubiquitin ligase: Insights into a molecular machine. Nat Rev Mol Cell Biol 5: 739-751, 2004.

21. Coomans de Brachène A and Demoulin JB: FOXO transcription factors in cancer development and therapy. Cell Mol Life Sci 73: 1159-1172, 2016.

22. Gründker C, Schulz K, Günthert $A R$ and Emons G: Luteinizing hormone-releasing hormone induces nuclear factor kappaBactivation and inhibits apoptosis in ovarian cancer cells. J Clin Endocrinol Metab 85: 3815-3820, 2000.

23. Tsitsipatis D, Klotz LO and Steinbrenner H: Multifaceted functions of the forkhead box transcription factors FoxO1 and FoxO3 in skin. Biochim Biophys Acta 1861: 1057-1064, 2017.

24. Carbajo-Pescador S, Mauriz JL, García-Palomo A and GonzálezGallego J: FoxO proteins: Regulation and molecular targets in liver cancer. Curr Med Chem 21: 1231-1246, 2014.

25. Procaccia S, Ordan M, Cohen I, Bendetz-Nezer S and Seger R: Direct binding of MEK1 and MEK2 to AKT induces Foxo1 phosphorylation, cellular migration and metastasis. Sci Rep 7: 43078, 2017.

26. Fu $\mathrm{Z}$ and Tindall DJ: FOXOs, cancer and regulation of apoptosis. Oncogene 27: 2312-2319, 2008

27. Ho KK, Myatt SS and Lam EW: Many forks in the path: Cycling with FoxO. Oncogene 27: 2300-2311, 2008.

28. Brunet A, Bonni A, Zigmond MJ, Lin MZ, Juo P, Hu LS, Anderson MJ, Arden KC, Blenis J and Greenberg ME: Akt promotes cell survival by phosphorylating and inhibiting a Forkhead transcription factor. Cell 96: 857-868, 1999.

29. Reagan-Shaw S and Ahmad N: RNA interference-mediated depletion of phosphoinositide 3-kinase activates forkhead box class $\mathrm{O}$ transcription factors and induces cell cycle arrest and apoptosis in breast carcinoma cells. Cancer Res 66: 1062-1069, 2006.

30. Prasad SB, Yadav SS, Das M, Govardhan HB, Pandey LK, Singh S, Pradhan S and Narayan G: Down regulation of FOXO1 promotes cell proliferation in cervical cancer. J Cancer 5: 655-662, 2014.

This work is licensed under a Creative Commons Attribution-NonCommercial-NoDerivatives 4.0 International (CC BY-NC-ND 4.0) License. 